7.

Verder blyven die van Towadjo mede verbonden en verpligt tot alle 't geene waar toe die van Macasser, soo voor als na het veroveren van Sambasso, ${ }^{1}$ ) door het Bonaayse contract als de nadere poincten, int hooftquartier Jacatra ${ }^{2}$ ) aengegaan ende bevestigt, verbonden en verpligt zyn voor sooveel als het haar eenigsints aplicabel zy.

8.

Die van Towadja sullende twee en vyftig duysent ryx ${ }^{s}$, dewelke Sijn Hoogheyt Palacca op het veroveren van de hooftstat Tosarra haar opgeleyt te betalen tot vergoedinge van Comp onkosten in desen oorlog, voldoen in vier moussons ${ }^{3}$ ), als een quart nu met een aldereersten ende soovoort de volgende moussonnen aen den anderen tot de volle betalinge toe, 't sy in goud, silver of juweelen elk naar zijn waerdije.

9.

Tot solemnele bevestinge van alle $t$ geene voorschreven staat, soo hebben den koning van Tosarra met de Tellolimpaijas in den hoofde deses alles genomineert, ider voor sig selven en gesamenlijk voor het gehele volk van Towadjo, desen onder het drinken van water, over haare crissen gegoten, op den Alcoran besworen ter presentie van de nevenstaande bontgenoten ende raadspersonen, die deesen meede soo versegelt als ondertekent hebben. - In 't casteel Rotterdam Macasser ady 23 December 1670 ende ondertek ${ }^{t}$ den 10 Januarij 1671. Onderstond Comps zeegel in rood lack nevens eenige Maleytse caracters. Laager: was getekent Maximiliaan de Jongh. Ter zijden was nog geteijkent Davit Harthouwer, Jan Franco, Johannes Mulder en Harman Hop.

\title{
CCCXXIX. BANDA.
}

\section{Maart 1671. ${ }^{4}$ )}

De opvolger van Jacob Cops als gouverneur van Banda, Antonie Hurdt, volgde de politiek van zijn voorganger en trachtte de eilandengroepen tus-

\footnotetext{
1) Samboepo.

2) Zie hiervóór, bldz. 415 .

3) Een der weinige voorbeelden van de mouson-tijdrekening, die ik in de contracten aantrof.

4) Uit het Contractboek.
} 
schen Banda en Timor steeds meer onder de suprematie van de Compagnie te brengen. Het onderstaand, ,verbond" met poeloe Babar was daarvan een der resultaten.

Verbond opgerigt tusschen ons onderge ${ }^{\mathrm{n}}$, afgesonden van de Ed. Anthonio Hurt, ${ }^{1}$ ) gouverneur en directeur over de eylanden van Banda en aenkleve derselve onder $t$ beleyt van de $\mathrm{Ed}^{\mathbf{e}}$ Heer Joan Maatsuyker, gouverneur generael over gants Nederlants Orienten wegens de Vereenigde Nederlantse Oostindise Comp: aen d'eene en de orancayen op 't eyland Babber, Kerry, Likarij, Liermot, hoofden over de negoryen Egirly, ${ }^{2}$ ) Likriar, ${ }^{2}$ ) Letilij, ${ }^{2}$ ) Liechob, ${ }^{2}$ ) Soamonan, $\left.{ }^{2}\right)$ Pallior, ${ }^{2}$ ) Lelehor, ${ }^{2}$ ) Elianahob, ${ }^{2}$ ) Mesbalij, ${ }^{2}$ ) Imilauloud, ${ }^{2}$ ) Letresij, ${ }^{2}$ ) gelegen op de Z.O. en O.Z.O. kant. Item orankaijen [van] Lodey, ${ }^{2}$ ) Tohang, ${ }^{2}$ ) Kokomey, ${ }^{2}$ ) Rindala, ${ }^{2}$ ) leggende om de Oost en N.O. syde van $d^{\circ}$. eyland. Op Wetang orankayen Payliery, Lutya, Nassuwawalij, Toedoedeley, Woetely, Salouwa van de negorye Socky, ${ }^{2}$ ) Tenwotte, ${ }^{2}$ ) Romelewan, ${ }^{2}$ ) Nocceatta, ${ }^{2}$ ) Woesijlij, ${ }^{2}$ ) Potto, ${ }^{2}$ ) rondsom $\mathrm{t}$ geheele landt gelegen op Wassello ${ }^{3}$ ), orangkayen Tiereky, Epiap, Massella, Suyhera, Maypoela, Kekin, Heyok over de negoryen Liray, ${ }^{2}$ ) Mesepaly, ${ }^{2}$ ) Palliou, ${ }^{2}$ ) Namoly, ${ }^{2}$ ) Sekertay, ${ }^{2}$ ) Biblewan, ${ }^{2}$ ) Sekily, leggende alle op Wetang, 't gantsche land door verspreyt, en voorts voor haarselven, hunne successeure en onderdanen, van d'andre zijde; te weten:

Dat de orangkayen voorm ${ }^{t}$ hun selven met haare successeuren gantschelyk overgeven aen de gehoorsaamheyt van de Nederlantse Oostindische Comp., haar stellende als onderdanen derselve, in welker voegen sy voorts onveranderlyk beloven, aen wel gem ${ }^{\text {te }}$ Comp. alleen, met uytsluijtinge van alle andere natien, 't sij blanke of swarte, haare stranden en landen te sullen openstelle ende geensints toestaen, dat ijmant anders daarop geadmitteert, veel wijniger met deselve eenige contracten, beloften ofte verbintenissen aengegaen werden nu nog nimmermeer.

Ende ten eijnde van derselver goede meyning en opregtigheijt te meer mogen versekert blyven, soo ist dat de Comp: by desen wert vrygestelt, om nu, off wanneer haar sulx sal gelegen komen, aldaar eenig volck, logie of fortres te leggen, in welk geval de orangkayen

1) Antonie Hurdt was gouverneur van Ambon geworden in 1669. (Encyclopaedie, II, bldz. 116 en Dagh-Register 1668-1669, Register).

2) ?

3) Wassela op Larat? (Veth, III, bldz. 1158). 
beloven, het volk in alles de behulpsame hant te bieden, indien het nodig zy, en voorts de logie off fortress, die de Comp. mogt resolveeren daar te leggen, te helpen opmaken.

Hiervoor verbind sig de Comp., de versogte bescherming over haar te nemen, evenals over de goede burgers en Mardijkers in Banda, tegens alle en yder die deselve eenige schaade ofte leet mogen aendoen ofte willen aendoen, als sy sulkx komen bekent maken en slaeken (?)

Het sal de gem $^{\text {te }}$ orankayen vrij staan, jaarlycs ofte soo dikwils het hun gelegen komt, met of sonder haare coopmanschappen in Banda te verschynen ofte haar volk derwaarts te laten vaaren, alwaar sy dan wel en naar behoren als vrinden en goede onderdanen sullen werden ontfangen en getracteert.

Welke bovenstaende articulen wy gesamentlyck voor ons, onse onderdanen en nakomelingen, beloven sonder eenige de minste infractie in alles promptelyck naar te komen ende agtervolgen, doende tot becragting van dien by wedersytse gewonelyke solemniteyten een eed van getrouwigh ${ }^{t}$ en wert de gemelte orankayen daar op een vlagge behandigt, om met deselve aen alle aencomende volkeren te betonen, dat sy syn bondtgenoten en onderdanen van de Comp.

Aldus gecontracteert ende beswooren in de hoeker Einkhoorn ${ }^{1}$ ), leggende geankert voor het eyland Wetang, ady 22 Maert 1671. Was getekent Nicolaas de Jamblinne ${ }^{2}$ ), Michiel de Ruijter, Mr. de Witte; dit merck gestelt by de orangkay Sikareij van de negory Ergili op Babber, dit merck van de orankay Liermot van de negory Likriar, dit beij de orankaij Kerry, orankay van de selve gesamentlijk van de negoryen Letijly, Liechob, Illamanoe, Pallior, Letelor, Mesbaly, Imilaulona, Letreh, Elmaclob, dit merck gestelt by den orangkaya Lodey van de negory Wetoky; dit merck gestelt bij de orankaij Tolang van de negory Bibleuwan, dit merck gestelt bij de orankay Kokowig van de negory Noray, dit gestelt by de orankay Hariack van de negorij Tineale, dit merck gestelt bij de opperste orankaij van Wetang, gen ${ }^{\mathrm{t}}$ Payliery, van'de negory Soycko; dit merk gestelt by de orangkay Tintya van de negory Tenewotto, dit merk gestelt bij de orankaij Natsuwawaly van Rommelawan, dit merk gestelt by de orankaij Toedaedelij van Noceatte, dit merk gestelt

1) De Eenhoorn, de Eekhoorn(?).

2) Vermoedelijk de Jan Blinne of Blimme van de vroeger gesloten contracten met deze eilandengroepen. Vgl. Register. 
bij de orancaij Woetely van de negorij Woerseyly, dit merk gestelt by de orankay Salouwa van de negory Potto, dit merk gestelt bey de orankay Tierlehy van de negory Lieray, dit merk gestelt bij de orankay Epiap van de negory Nissipaly, dit gestelt by de orangkay Massella van de negory Pallior, dit merk gestelt by de orankay Teulera van de negory Momoly, dit merck'gestelt by de orankay Maypoela van de negory Sehetay, dit merk gestelt by de orankaya Eyok van de negorij Lekily.

\section{SUMATRA'S WESTKUST.}

\section{i Augustus 1671. ${ }^{1}$ )}

Ook hier op Sumatra's Westkust werd geregeld voortgegaan met de zaken te stabileeren en het gezag der O. I. C. uit te breiden,waarbij de vorst van Menangkabaoe en ook Padang als stroopoppen dienden, welke laatste plaats zich daardoor in gezagsuitbreiding en -versterking mocht verheugen (Dagh-Register 1670-1671, bldz. 399, v.v. Vgl. ook Mac Leod, Sumatra, Indische Gids, Augisstus 1904, bldz. 1281, v.v.) De belooning voor de O.I.C. in financieele voordeelen bleef niet uit: de inkomende rechten, vroeger ten bate van Atjèh geheven, werden ons overgedragen. Die van Padang deden dit gaarne omdat het een geschikt middel was, om de voor hen schadelijken import-smokkelhandel in katoentjes tegen te gaan.

Vrywillige opdragt, gedaan by de algemeene regenten tot Padang aen d'Ed. Comp ${ }^{1 e}$, nopende de 10 perc $^{\text {te }}$ thol, van de uitheemse negotianten te ligten.

Compareerende voor mij, Joannes Metman, ${ }^{2}$ ) onderkoopman, fiscaal, mitsgaders gequalificeert secretaris in lands saaken op en langs dese Westkust Sumatra, ter presentie van de naargen ${ }^{\text {en }}$ getuijgen, panglima Radja ende d'algemeyne regenten ${ }^{3}$ ) tot Padang, dewelke verklaren hoe datse uyt eygen beweging ende besondere inclinatie aen de Comp ${ }^{\text {ie }}$ in recompens voor eeuwig en altoos voor haar en alle haare nakomelingen schenken ende overgeven al sulken thol ende geregtigheyt, die alhier ten tyde der Aetchinse regering

1) Uit het Contractboek.

2) Schrijffout voor „Melman”. Men zie over hem Dagh-Register 1670-1671, bldz. 247, 296, 399 v.v. Valentijn, V, 1, Sumatra, bldz. 36, 38.

3) Het Dagh-Register 1670-1671, bldz. 398, spreekt van "panglema Radja en de 12 raedsheeren in de stad Padang." 